\title{
As Repercussões das Operações Urbanas em Belo HORIZONTE: O CASO dA OCUPAÇÃO dO IZIDORO
}

\section{e-Xactal}

ISSN: 1984-3151
The Repercussions of Urban Operations in Belo Horizonte:

THE OF OCCUPATION OF IZIDORO

\section{Reginaldo Magalhães de Almeida ${ }^{1}$; Juliana Lamego Balbino Nizza ${ }^{2}$; Amanda Pereira de Oliveira Diniz ${ }^{3}$; Jorge Eulampio Monteiro Junior ${ }^{4}$}

\footnotetext{
1 Doutor em Arquitetura e Urbanismo. Professor dos Cursos de Arquitetura e Urbanismo, de Engenharia Ambiental e Engenharia da Produção Civil da Universidade FUMEC. ralmeida@fumec.br.

2 Mestre em Direito Empresarial. Professora dos Cursos de Engenharia Civil e Engenharia de Produção Civil da Universidade FUMEC. Email: jlamego@fumec.br.

3 Graduanda do Curso de Arquitetura e Urbanismo da Universidade FUMEC. Email: amandadinizpod@gmail.com.

4 Graduando do Curso de Arquitetura e Urbanismo da Universidade FUMEC. Email: ïmem@hotmail.com.
}

Recebido em: 03/07/2016 - Aprovado em: 11/05/2017 - Disponibilizado em: 31/05/2017

RESUMO: Instrumentos jurídicos e urbanísticos como as Operações Urbanas refletem diretamente no cotidiano das cidades. Cada vez mais utilizado, entende-se que o conhecimento da aplicação das Operações Urbanas é importante para os profissionais do campo do Direito e da Arquitetura. Portanto, este artigo analisa criticamente as repercussões do processo de implementação das Operações Urbanas em Belo Horizonte. Entende-se que a ineficácia da implementação desse instrumento pode estimular o surgimento de processos urbanos conflitantes, como as ocupações de propriedades privadas da cidade. Como estudo de caso da implantação dessa lei, selecionou-se a "Operação Urbana do Izidoro", regulamentada pela Lei $n^{\circ}$ 9.959/10 de Belo Horizonte. Prevista para ser implantada em uma grande área vazia de domínio privado da cidade, atualmente vem passando por um dos maiores processos de ocupação de população de baixa renda de Minas Gerais. Utilizou-se ainda como metodologia, primeiramente, uma ampla revisão bibliográfica de autores referenciais do campo da Arquitetura e do Direito e posteriormente, realizou-se um levantamento de dados em processos técnico-administrativos da Prefeitura de Belo Horizonte e visitas de campo. Esses dados foram analisados e depois consolidados para a utilização neste artigo. Ao final, como resultado, conclui-se que, em que pese os discursos sobre as Operações Urbanas como um instrumento de desenvolvimento urbano, conforme definido na lei conhecida como Estatuto da Cidade, em Belo Horizonte, seu uso vem se dando principalmente como um instrumento de viabilização da implantação de grandes empreendimentos imobiliários, que, ao desconsiderarem alguns segmentos sociais, acabam por contribuir para o aumento das desigualdades socioespaciais da cidade e dos processos de ocupações. Além disso, destaca-se a distância existente entre as intenções estabelecidas na elaboração desse instrumento e a sua real efetividade.

PalaVRAS-CHAVE: Belo Horizonte. Operação Urbana. Ocupações Urbanas. Região do Izidoro.

ABSTRACT: Legal and urbanistic instruments such as the Urban Operations directly reflect the daily life of cities. Increasingly used, it is understood that knowledge of the application of the Urban Operations is important for practitioners of the law and architecture field. Therefore, this article critically examines the impact of the Urban 
Operations implementation process in Belo Horizonte. It is understood that the ineffectiveness of the implementation of this instrument can stimulate the emergence of conflicting urban processes, such as the occupation of private property of the city. As if the implementation of this law study, we selected the "Urban Operation of Izidoro", regulated by Law No. 9.959/10 of Belo Horizonte. Expected to be deployed in a large empty area of private domain of the city, is currently undergoing one of the largest low population occupation processes income of Minas Gerais. Firstly, the methodology involved the bibliographical review of reference authors from the field of Architecture and Law, in technical-administrative processes of the City Hall of Belo Horizonte and field visits. This data was analyzed and then consolidated for use in this article. At the end, as a result, it is concluded that, in spite of the speeches about Urban Operations as an instrument of urban development, as defined in the Law known as the Statute of the City, in Belo Horizonte, its use is mainly given as an instrument of making feasible the implantation of large real estate enterprises, which, by disregarding some social segments, end up contributing to the increase of socio-spatial inequalities of the city and of occupation processes. In addition, the distance between the intentions established in the elaboration of this instrument and its actual effectiveness is highlighted. KEYWORDS: Belo Horizonte. Urban operation. Urban occupations. Izidoro Region.

\section{INTRODUÇÃO}

$\mathrm{Na}$ produção do espaço urbano de Belo Horizonte, capital de Minas Gerais, desde a sua gênese até os dias atuais, destaca-se a aplicação de diversas legislações urbanísticas, como o Plano Diretor, a Lei de Parcelamento, Ocupação e Uso do Solo (LPOUS), Posturas, dentre outras. Nessas leis estão regulamentados diversos instrumentos urbanísticos que visam atender aos princípios que embasam as legislações. A análise dos efeitos da aplicação desses instrumentos pode contribuir para ampliar a compreensão dos meandros do processo de expansão urbana, bem como os seus significados na formação socioespacial da cidade.

As configurações do espaço, como resultado desses instrumentos urbanísticos, convidam a pensar os vários caminhos trilhados por Belo Horizonte, no decurso de sua expansão territorial, aguçando os olhares questionadores sobre a sua história, na qual está registrado o seu processo de formação.

A legislação urbanística constitui instrumento por meio do qual o Poder Público atua no controle das atividades de planejamento, parcelamento, ocupação e uso do solo nas cidades. Esse controle tem, segundo juristas como Meirelles (2011), o objetivo do ordenamento urbano.
O art. 30, inciso VIII, da Constituição da República de 1988, dispõe que compete aos Municípios "[...] promover, no que couber, adequado ordenamento territorial, mediante planejamento e controle do uso, do parcelamento e da ocupação do solo urbano" (BRASIL, 2011). Cabe à legislação urbanística estabelecer limites às ações que produzem o espaço urbano visando uma maior qualidade de vida na cidade. Essas ações, que fazem parte do cotidiano das pessoas que usam o espaço, estão relacionadas com as necessidades próprias, como mobilidade, moradia, trabalho, educação, saúde, alimentação e lazer. Desse modo, são regulamentadas, não só as ações de construção do espaço urbano, por meio de parcelamentos do solo e edificações, mas também as atividades dentro desse espaço, visando ao bem comum e à harmonia social.

Em 2001, foi regulamentado um importante instrumento jurídico e urbanístico denominado como Operações Urbanas Consorciadas. Em sua tese de doutoramento, Monteiro (2014) conclui pela necessidade dos pesquisadores avançarem com as experiências e críticas com relação ao instrumento das Operações Urbanas, de forma a aproveitar as possibilidades do instrumento, avaliar os efeitos socioespaciais que promove, usufruindo dos benefícios de gestão do espaço urbano. 
Diversos autores, como a professora Maricato (2015), consideram que a ocupação urbana de terrenos privados pela população de menor poder aquisitivo e sem habitação própria é resultante, dentre outros, da exclusão dessa população do processo considerado como formal de produção da cidade regulamentado por diversas legislações urbanísticas.

Nesse contexto, este artigo tem o objetivo de analisar as repercussões da implementação do instrumento jurídico e urbanístico das Operações Urbanas na produção do espaço urbano de Belo Horizonte. Entende-se que a ineficácia da implementação da lei da Operação Urbana pode estimular processos urbanos conflitantes, como as ocupações de propriedades privadas por segmentos sociais excluídos do processo de produção da cidade.

Para o jurista e professor Silva (2007), referência nos estudos jurídicos, a implantação de uma legislação é um processo que se inicia com a idealização da lei, passa por sua redação, apresentação ao Poder Legislativo, discussão, votação, aprovação, promulgação e publicação em Diário Oficial. Já a implementação da lei só começa depois que ela estiver implantada. Com relação à análise da implementação de uma legislação, cabe verificar, se ela está de fato sendo cumprida e se está produzindo os efeitos desejados.

Como objeto de discussão neste artigo, selecionou-se a Operação Urbana do Izidoro, proposta para uma das últimas áreas vazias e de domínio privado da cidade e que foi regulamentada e detalhada na Lei ${ }^{\circ}$ 9959/10 de Belo Horizonte. O objetivo dessa Operação Urbana, em fase de implementação, era o de viabilizar a construção de um grande empreendimento imobiliário voltado para as classes de maior poder aquisitivo da cidade. Em 2011, iniciou-se o processo de aprovação dos projetos de licenciamento junto aos órgãos públicos necessários para sua implantação.
Atualmente, a área da Operação Urbana passa por um processo de ocupação informal promovido por setores sociais de baixa renda.

Para desenvolvimento deste artigo, foram realizadas ampla revisão bibliográfica de autores do campo da Arquitetura e do Direito, pesquisas e análises documentais, baseadas nos documentos arquivados pela Prefeitura de Belo Horizonte (PBH) e que estão disponíveis ao acesso público. A análise envolveu também pesquisas em reportagens, teses e visitas de campo.

Este artigo fez parte de uma pesquisa denominada "Possibilidades do uso das Operações Urbanas Consorciadas como instrumento de regularização urbanística: o caso de Belo Horizonte". Esta pesquisa objetivou verificar as possibilidades da utilização do instrumento denominado Operações Urbanas Consorciadas, a partir do estudo de operações aprovadas em Belo Horizonte. Contou com o apoio e financiamento do ProPIC/FUMEC/2015/2016 e da FUNADESP.

Em Belo Horizonte, o instrumento das Operações Urbanas vem sendo utilizado desde que foi inserido na Lei n`7.165/96, Plano Diretor (MONTEIRO, 2014). Antecedendo ao Estatuto da Cidade, essa lei definiu que as Operações Urbanas são instituídas visando:

[...] a alcançar as finalidades da implantação de
equipamentos estratégicos para o desenvolvimento
urbano; otimização de áreas envolvidas em
intervenções urbanísticas de porte e reciclagem em
áreas consideradas subutilizadas; implantação de
Programas de Habitação de Interesse Social;
ampliação e melhoria da Rede Estrutural de
Transporte Público Coletivo; implantação de
espaços públicos; valorização e criação de
patrimônio ambiental, histórico, arquitetônico,
cultural e paisagístico; melhoria e ampliação da
infraestrutura e da Rede Viária Estrutural;
dinamização de áreas visando à geração de
empregos. Segundo a legislação federal, nas Operações Urbanas podem ocorrer a modificação de índices e características de parcelamento, ocupação e uso do solo e subsolo, bem como alterações das normas 
edilícias, considerando-se o impacto ambiental delas decorrente e o impacto de vizinhança; regularização de construções, reformas ou ampliações executadas em desacordo com a legislação vigente.

Desde 1996 até 2014, foram aprovadas diversas Operações Urbanas em Belo Horizonte. Nesse conjunto de operações, destaca-se a do Izidoro, uma enorme área privada, vazia e ambientalmente frágil, localizada próxima à divisa da região norte de Belo Horizonte com o munícipio de Santa Luzia.

\section{ObJetivos do InStRUmento JuRídico URBanístico das Operações Urbanas}

O capítulo de "Política Urbana" (artigos 182 e 183) da Constituição da República de 1988 estabelece as diretrizes gerais da política urbana com o objetivo principal do desenvolvimento das funções sociais da cidade e a garantia do direito a cidades sustentáveis (BRASIL, 2011). Regulamentando esses artigos, o Estatuto da Cidade prevê os instrumentos de política urbana, os quais são divididos em instrumentos de planejamento, institutos tributários e financeiros e institutos jurídicos e políticos. Nesses últimos estão previstas as Operações Urbanas, qualificadas como consorciadas.

No livro Direito Urbanístico Brasileiro, Silva (2014) considera que as Operações Urbanas são entendidas como "[...] toda atuação urbanística que envolve alteração da realidade urbana com vista a obter nova configuração da área". Logo, as "operações urbanas" têm como objetivo proporcionar o desenvolvimento urbano e são "consorciadas" por se tratarem de uma espécie de parceria público-privada, já que é necessária a cooperação entre Poder Público municipal e diferentes agentes sociais.

Nesse sentido, afirma o professor Carvalho Filho, (2005), "[...] que o grande fundamento das operações urbanas consorciadas é de fato a parceria entre o setor público e o privado".

Complementando a afirmativa anterior, o jurista e mestre em Direito Urbanístico Lomar (2010) afirma que ainda existem outros objetivos a considerar para as Operações Urbanas, tais como a realização de transformações estruturais, melhorias sociais e a valorização ambiental.

O Estatuto da Cidade dispõe em seu Artigo 33, que uma lei específica deverá estabelecer um plano de Operação Urbana consorciada contendo, por exemplo, a definição da área a ser atingida, o programa básico de ocupação da área; programas de ocupação e de atendimento econômico e social, finalidades da operação, forma de controle da operação, com a participação obrigatória de representantes da sociedade civil, dentre outros (BRASIL, 2001).

A definição da área a ser atingida é necessária, na medida em que a Operação Urbana não deve extrapolar seu perímetro. Nos programas de ocupação e de atendimento econômico e social são definidas as intenções do Poder Público para a área atingida e para a população afetada pela operação, como, por exemplo, os instrumentos e padrões urbanísticos, regularizações, provisão de equipamentos urbanos, dentre outros. Além disso, o Poder Público define as finalidades da operação e seus objetivos ao utilizar o instrumento, visando sempre ao interesse público.

Observa-se assim que, em sua concepção, a Operação Urbana trata-se de uma importante norma ou instrumento jurídico e urbanístico, eficaz para o desenvolvimento urbano.

Para o professor Cavalieri Filho (1998: 75), "[...] uma norma é eficaz quando produz os efeitos almejados". Ou seja, é eficaz a norma que atinge os seus objetivos, que realiza as suas finalidades, que atinge $o$ alvo porque está ajustada ao fato. Quanto mais adequada e atrelada a lei estiver à realidade social, 
mais eficaz ela será, pois abarcará os verdadeiros conflitos e problemas para os quais foi promulgada. Por outro lado, uma norma ineficaz é aquela que não se adequa aos seus fins expressos, pois não realiza 0 fim social que a justifica.

Silva (2007) afirma que:

[...] a eficácia consiste na capacidade de atingir os objetivos nela traduzidos, que vêm a ser, em última análise, realizar os ditames jurídicos objetivados pelo legislador.

Assim, considera-se que a análise da eficácia ou a ineficácia de uma legislação, como no caso das Operações Urbanas, passa pela comparação entre a finalidade prevista para a norma e a sua implementação.

\section{A Operação Urbana do IZIDORO}

A Região do Izidoro localiza-se no território conhecido como Vetor Norte de Belo Horizonte e da Região Metropolitana de Belo Horizonte (RMBH), abrangendo uma área total de $9,5 \mathrm{~km}^{2}$ (maior que a área interna à Avenida do Contorno de Belo Horizonte, projetada por Aarão Reis, no final do Século XIX, e que possui aproximadamente $8,9 \mathrm{~km}^{2}$ ). Delimitada por bairros populares, como Zilah-Spósito, Ribeiro de Abreu e Tupi, a região é marcada por ocupações irregulares.

Uma das principais características físicas da região é a de abrigar vultosa extensão de área verde preservada, formando um ecótono de cerrado com mata atlântica, contendo cerca de 280 nascentes de água e 64 córregos. A rede hídrica da região liga o Córrego do Izidoro ao Ribeirão do Onça, que irá abastecer e integrar a Bacia do Rio das Velhas, principal fonte de abastecimento de água de Belo Horizonte (BELO HORIZONTE, 2011).

O interesse de preservação ambiental evidenciado pelas características da região foi oficializado por leis municipais que a demarcaram como Área de
Diretrizes Especiais (ADE do Izidoro, LPOUS $\mathrm{N}^{\circ}$ 8.137/2000) e determinaram usos restritos compatíveis com a sua proteção sustentável. (BELO HORIZONTE, 2000).

O Vetor Norte de Belo Horizonte foi alvo de diversos investimentos realizados pelo Estado, para alavancar projetos estratégicos, que impulsionaram sua expansão e valorização, como a obra de mobilidade da Linha Verde, a implantação da Cidade Administrativa e a reforma do Aeroporto de Confins (ALMEIDA, MONTE-MÓR, 2015).

A captura da valorização imobiliária da região do Izidoro pelo mercado, através de empreendimentos de grande porte e possível venda de lotes, implicará, portanto, na apropriação das mais-valias fundiárias (a valorização econômica) advindas de intervenções do Estado. Esse processo combinado de aproveitamento privado de investimentos públicos e desvirtuamento dos instrumentos urbanísticos corrobora e acentua as desigualdades socioespaciais presentes na $\mathrm{RMBH}$.

Nesse sentido, foi aprovada a nova LPUOS de Belo Horizonte, Lei $n^{\circ}$ 9.959/10 (BELO HORIZONTE, 2010). Tal lei apresenta um capítulo que trata especificamente sobre a Operação Urbana do Izidoro. O processo para elaboração do citado capítulo compreendeu um levantamento pormenorizado de toda a área e seu entorno, incluindo mapeamento hidrogeológico, vegetação, corredores, infraestrutura de saúde, educação, índices socioeconômicos, dentre outros, procurando determinar um modelo de uso e ocupação para a área, compatível com os diversos interesses e demandas.

A lei municipal $n^{\circ} 9.959 / 10$ definiu as porções passíveis de ocupação e as que deveriam ser preservadas e recuperadas, dividindo-as de acordo com o grau de proteção. Algumas áreas seriam destinadas à preservação de nascentes, de cursos d'água e da cobertura vegetal de cerrado. A ocupação seria proibida em tais aéreas; entretanto o seu 
potencial construtivo poderia ser transferido para as outras áreas, quais sejam, as de proteção elevada e de proteção moderada (BELO HORIZONTE, 2016).

Frente às características ambientais, as LPUOS $\mathrm{n}^{\circ}$ $7.166 / 96$ e $8.137 / 2000$ definiram zoneamentos mais restritivos para a região do Izidoro, como ZP2 (zoneamento para regiões predominantemente ocupadas, de proteção ambiental, histórica, cultural, arqueológica ou paisagística ou em que existam condições topográficas ou geológicas desfavoráveis, onde devem ser mantidos baixos índices de densidade demográfica) e ZPAM (zoneamento para regiões que, por suas características e pela tipicidade da vegetação, destinam-se à preservação e à recuperação de ecossistemas). Esses zoneamentos inviabilizariam uma ocupação imobiliária maior da área, já que os parâmetros urbanísticos eram muito restritivos.

Por isso, a fim de atender aos interesses dos proprietários para parcelar a região do Izidoro e viabilizar um empreendimento imobiliário com uma grande área construída, o que possibilitaria a diluição dos custos de implantação de infraestrutura, foi necessário aprovar uma Operação Urbana, que introduziu parâmetros mais permissíveis para ocupação da área.

De forma sintética, a Operação Urbana viabiliza um projeto urbanístico especial que permite um maior adensamento nas áreas propícias à ocupação; a transformação de grandes áreas com vegetação significativa em parques e reservas ecológicas com acesso público e integradas às áreas de proteção dos cursos d'água; a promoção da recuperação ambiental das áreas de preservação ambiental; a preservação das visadas de topo e de fundo de vale e a implantação de toda a infraestrutura necessária, como sistema viário, equipamentos urbanos e comunitários (BELO HORIZONTE, 2011).
O Plano de Ocupação da Região do Izidoro previsto na LPUOS propõe um modelo verticalizado, com taxas de permeabilidade mais elevadas, tentando assegurar e ampliar a preservação de áreas de importância ambiental.

Também faz parte do sistema viário da Operação do Izidoro a implantação de importantes vias para a melhoria da mobilidade da cidade: A via 540, que fará a interligação entre a Rodovia MG-20 e a Avenida Cristiano Machado, de forma a promover a melhoria da articulação interna da Região Norte do Município e a Via Norte-Sul, que cortará a Região Norte do Município, no sentido norte-sul. (BELO HORIZONTE, 2011) (Figura 1).

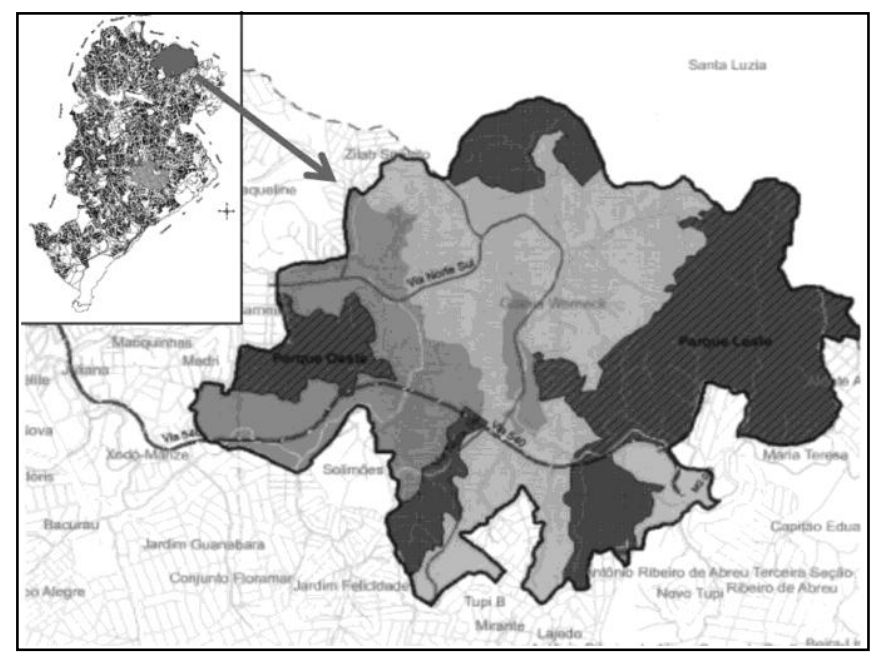

Figura 1 - Localização e Plano de Ocupação da Operação Urbana do Izidoro. De cinza claro e médio, áreas possíveis de urbanização. Cinza escuro, futuros parques

Fonte - BELO HORIZONTE, 2010 - adaptado pelos autores.

A PBH definiu os equipamentos urbanos e comunitários previstos para a área da Operação Urbana no seu total e sua implantação deverá ocorrer progressivamente, de acordo com o número de unidades habitacionais existentes, como por exemplo, 15 Unidades Municipais de Educação Infantil; 20 Escolas de Ensino Fundamental/Escola Integrada, 8 Escolas de Ensino Médio, 2 Escolas Profissionalizantes, 14 centros de saúde, dentre 
outros. É prevista para a área da Operação Urbana a implantação dos seguintes parques públicos: Parque Leste, com área total estimada em $2.300 .000 \mathrm{~m}^{2}$, ou seja, uma área próxima à do atual Parque das Mangabeiras, maior área verde da cidade de Belo Horizonte, e o Parque Oeste, com área total estimada em $500.000 \mathrm{~m}^{2}$.

Proprietários de cerca de metade da área do Izidoro, juntamente com uma grande construtora da capital, deram início ao processo de licenciamento ambiental, com vistas a construir um grande empreendimento imobiliário voltado para a população de média e alta renda. Em outubro de 2015, os proprietários apresentaram um projeto urbanístico, detalhando o Plano de Ocupação da região, obtendo a Licença Prévia no Processo de Licenciamento Ambiental (BELO HORIZONTE, 2016) (Figura 1). O restante da área ainda não possui projetos em tramitação na Prefeitura.

Observa-se, que a produção social do espaço resultante da Operação Urbana do Izidoro busca as abstrações representadas pelo dinheiro e pela mercadoria, já que se trata de um grande empreendimento imobiliário privado. Essa abstração apoia-se em grandes grupos empresariais ou capitalistas, que, como afirmou o filósofo francês Lefèbvre (1991), espacializam suas ideologias.

O projeto urbanístico licenciado é subdividido em grandes bolsões urbanizados, fragmentados entre as áreas de preservação permanente, que compreendem $32 \%$ da área total do terreno que é 350 hectares, sendo que os restantes $68 \%$ serão preservados.

O plano estabelecido na lei da Operação Urbana é da construção de 75 mil apartamentos, sendo que alguns serão destinados para o Programa Minha Casa Minha Vida, para a faixa de 6 a 10 salários mínimos e outros voltados para as classes média e alta, sem contar os usos comercial e institucional.
A alta densidade visa aumentar os ganhos do empreendimento, em razão dos altos custos de implantação, devido à urbanização espraiada e ao pequeno percentual de áreas passíveis de construção. (BELO HORIZONTE, 2011) (Figura 2).

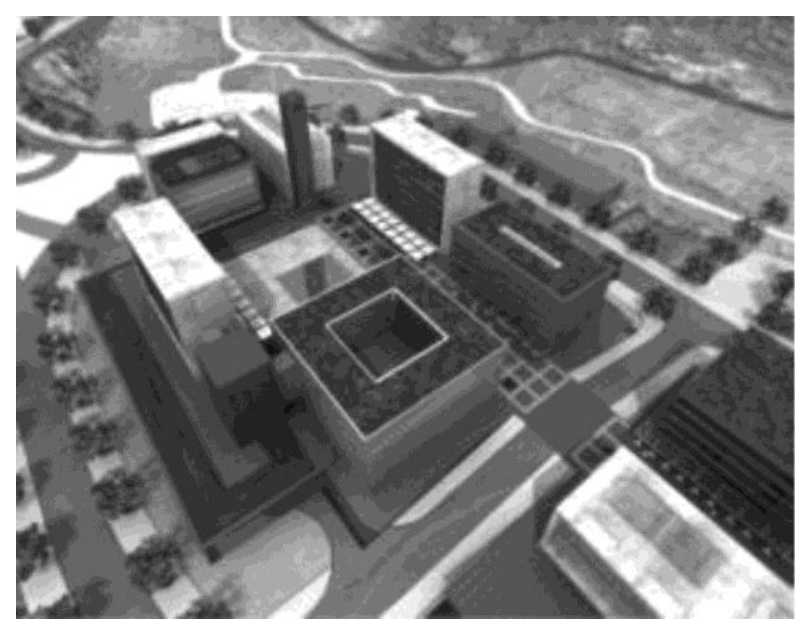

Figura 2 - Perspectiva de parte do projeto urbanístico proposto para o Izidoro Fonte - BELO HORIZONTE, 2011.

Entende-se que a implantação do projeto urbanístico resultante da Operação Urbana do Izidoro contribuirá ainda mais para consolidar a segregação socioespacial da cidade. Isso porque, ocupando uma região carente de infraestrutura, a implantação da Operação Urbana do Izidoro ampliará ainda mais a fragmentação da região, pois, enquanto na área são previstos bolsões urbanizados, dotados de equipamentos urbanos e comunitários, envolvidos por espaços verdes, o entorno continuará sendo formado por bairros com baixa oferta de infraestrutura urbana. Além disso, não existem garantias de que a demanda por equipamentos ficará restrita apenas à área do empreendimento.

Os regulamentos previstos na Operação Urbana visam protegê-la quanto às possíveis variações nas tipologias e formas de ocupação, ou seja, busca-se uma homogeneização como forma de proteção dos investimentos imobiliários. E, por último, trata-se de um empreendimento que aumentará a hierarquização da cidade, já que prevê o acesso de classes de maior 
poder aquisitivo, revelando as formas da segregação urbana. Entretanto, paralelamente ao licenciamento do projeto urbanístico da Operação Urbana nos órgãos públicos, começou um forte processo de ocupação da área por famílias de baixa renda, organizadas em comunidades, amparadas pelos movimentos de moradia de Belo Horizonte (Figura 3).
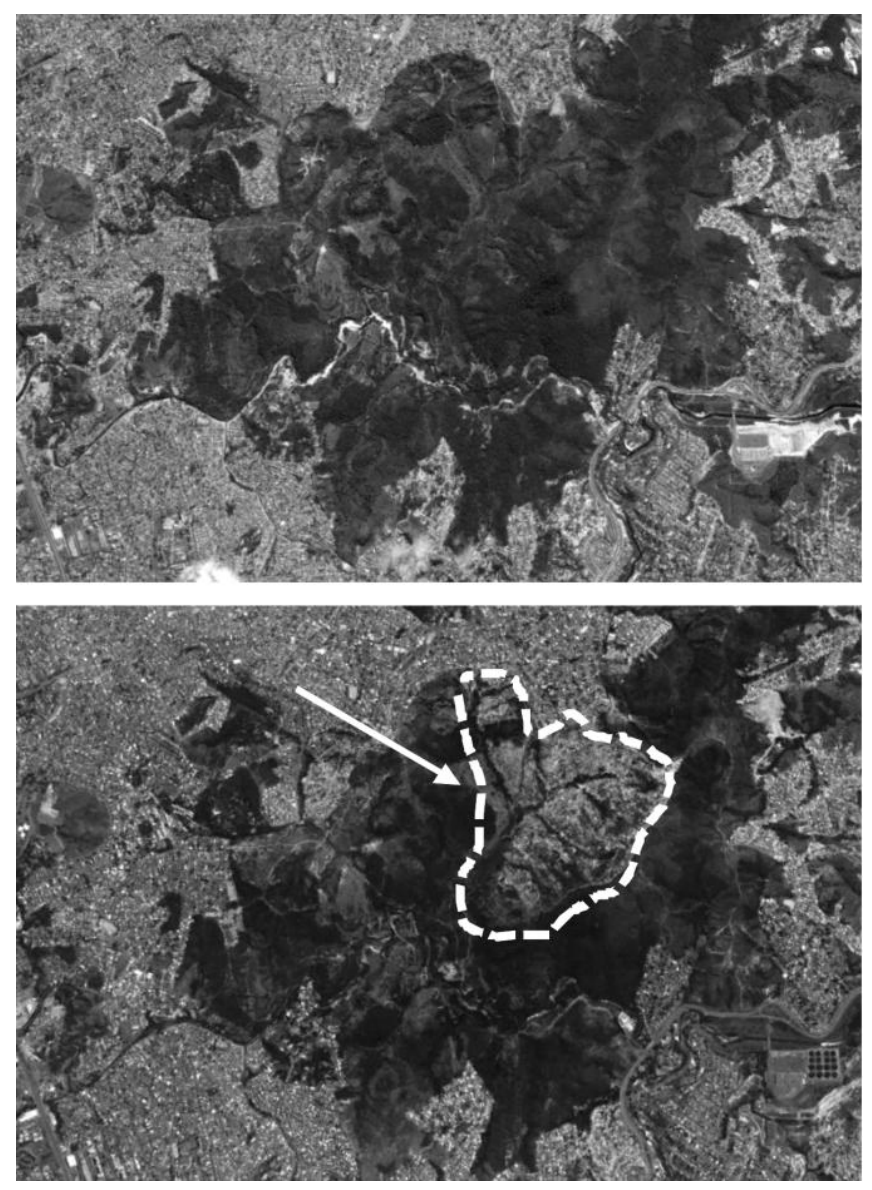

Figura 3 - Região do Izidoro em 2011 e a mancha da ocupação em 2016

Fonte - BELO HORIZONTE, 2016 - adaptado pelos autores.

Surgiram, oficialmente, as ocupações denominadas como Rosa Leão, Vitória e Esperança, embora relatos de alguns moradores revelem residentes no espaço, há pelo menos três décadas (URBEL, 2014). Em junho de 2016, cerca de $1 / 4$ da área estava em processo de ocupação.

A necessidade de habitação em Belo Horizonte é constatada pelos índices oficiais. De acordo com dados do IPEA de 2010, o déficit habitacional da cidade corresponde a 150 mil moradias. A ocupação de terrenos vazios e subutilizados como o do Izidoro aparece, portanto, como uma solução que a sociedade civil encontra, frente à ineficiência do Estado em suprir essa necessidade. Os programas oficiais, como o Programa Minha Casa Minha Vida financiam habitações para as camadas acima de 3 salários mínimos, ou seja, não atendem ao grande déficit da população sem moradia no Brasil que se situa abaixo dos 3 salários (IPEA, 2015).

Parte das áreas ocupadas do Izidoro consiste em bolsões, onde a vegetação era menos expressiva e a topografia mais plana, embora algumas áreas com maior declividade e de preservação ambiental tenham sido ocupadas também. A maioria das casas é de alvenaria e foram construídas com as economias dos moradores. (Figura 4).

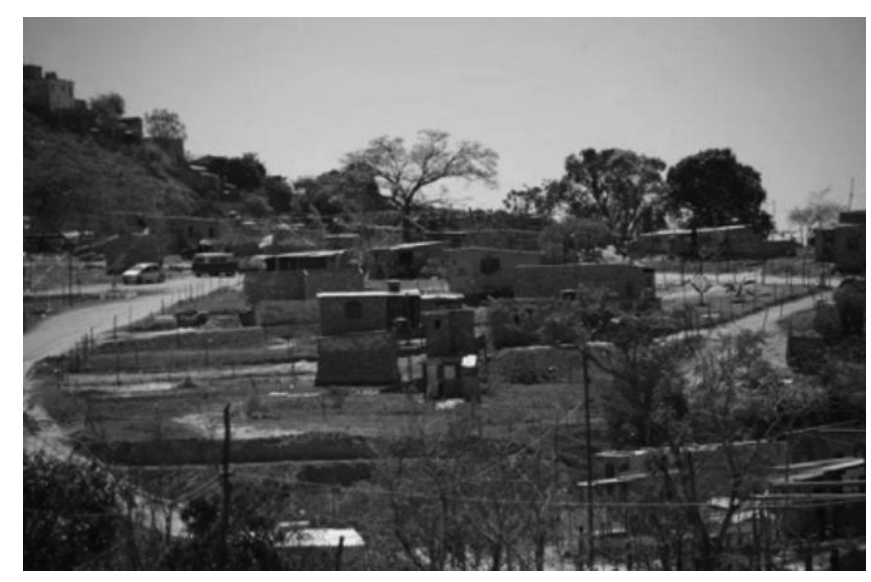

Figura 4 - Ocupações do Izidoro Fonte - DIARIOLIBERDADE, 2016.

As casas convivem com habitações feitas de capa de carro, sacolas plásticas, lonas, materiais recicláveis, etc., implantadas em parcelas do terreno sem qualquer infraestrutura, demonstrando a precariedade econômica das famílias e a vulnerabilidade a qual estão expostas grandes parcelas desta população

Atualmente, o licenciamento do projeto urbanístico da Operação Urbana do Izidoro está paralisado em meio ao imbróglio de titularidades, disputas por heranças, 
as quais impossibilitam a aprovação do parcelamento da área e a continuidade da aprovação na Prefeitura. Aliado a isso, tem-se a pressão da população. Não existe indicativo, no entanto, de que ele não possa ser retomado a partir da desocupação da área (BELO HORIZONTE, 2016).

Desde o anúncio de que as áreas seriam desocupadas, moradores e movimentos sociais se articulam em uma rede de solidariedade formada por ativistas dos Direitos Humanos, professores universitários, artistas, Igreja Católica, jornalistas, arquitetos, advogados, entre outros grupos. A partir de 2013, depois que foi concedida liminar para os pedidos de reintegração de posse, que autorizou o desalojamento das famílias residentes nas três ocupações do Izidoro, começou a ser travada uma batalha jurídica pelos moradores, amparados pelo Ministério Público e pela Defensoria Pública (DIARIOLIBERDADE, 2016).

Embora se verifique a imposição do Estado e do mercado pela expansão do espaço que atende aos interesses de ambos, através do instrumento urbanístico e jurídico da Operação Urbana, entendese que essa imposição, conforme defende Lefèbvre (1991), não consegue destituir completamente, como é o caso da ocupação do Izidoro, as contradições da realidade prática e os conflitos concernentes à própria lógica econômica e política.

\section{Considerações Finais}

O espaço da modernidade, a partir do momento em que as condições de salubridade das cidades atingem seu pronto crítico, passa a ser o resultado da ação combinada entre o mercado e o Estado. O objetivo do primeiro é primordialmente o lucro e o do segundo resulta na garantia do controle do solo, o que acaba por favorecer os objetivos capitalistas. Nesse contexto, assumem importância as legislações urbanísticas e os respectivos instrumentos que elas consolidam, como é o caso das Operações Urbanas.

Observa-se, em casos como o da Operação Urbana do Izidoro, a ineficácia desse instrumento quanto aos objetivos propostos, posto que, com o objetivo de promover o desenvolvimento urbano e de uma cidade mais justa para todos, como previsto no Estatuto da Cidade, acaba por, ao elitizar sua proposta, estimular processos de ocupação pela população carente e excluída do processo da operação.

Em que pese os discursos sobre as Operações Urbanas como um instrumento de desenvolvimento urbano, em Belo Horizonte, seu uso é verificado principalmente como um instrumento de viabilização, através da mudança de parâmetros urbanísticos e contrapartidas, para a implantação de grandes empreendimentos imobiliários que impactam consideravelmente na estrutura socioespacial da cidade, acirrando problemas tais como, de mobilidade e hierarquização do espaço.

O processo de produção do espaço urbano em metrópoles como Belo Horizonte, contando com o apoio de instrumentos legais como as Operações Urbanas, está marcado por uma união entre o Estado e os agentes macroeconômicos, distanciando do discurso de uma cidade mais justa para todos, como anteriormente idealizado nas origens no Estatuto da Cidade. Tal situação contribui para o aumento das desigualdades socioespaciais em Belo Horizonte, já que as minorias são desconsideradas, como é o caso da Operação do Izidoro.

Por abrigar diferentes conflitos da produção do espaço, a ocupação do Izidoro representa um microcosmo da metrópole contra as arbitrariedades que colocam movimentos sociais em campo oposto aos poderes político, judiciário e empresarial.

A Operação Urbana do Izidoro teve como objetivo viabilizar de forma sustentável a ocupação da região, através da utilização de contrapartidas da iniciativa 
privada. Identifica-se, como um dos maiores desafios desse instrumento urbanístico, a busca pelo equilíbrio entre os interesses público e privado. É inegável que o interesse da iniciativa privada deve ser garantido, sem, contudo, olvidar o que instituiu o Plano Diretor e o Plano de Ocupação da referida área.

Entende-se que a eficácia de uma lei está atrelada à sua adequação à realidade social, pois, dessa forma, abarcará os verdadeiros conflitos e problemas para os quais foi criada.

Ocorre que, paralelo ao interesse legal de ordenação protetiva desse espaço, está o interesse do mercado imobiliário de se apropriar de uma das últimas grandes áreas privadas e não parceladas em Belo Horizonte. Interesse esse, que encontra amparo e proteção legal num emaranhado ambíguo de legislações que buscam combinar proteção ambiental, urbanização técnica e social, habitação social e obras de infraestrutura, para proveito unilateral do mercado imobiliário.

A implementação da Operação Urbana, como instrumento da política urbana conforme prescreve o Estatuto da Cidade, mais do que sua especificidade legal, precisa adequar-se às necessidades locais e, não menos, considerar a minimização dos impactos derivados dos conflitos urbanos, a partir da busca pelo equilíbrio econômico e pela diversidade social.
$\mathrm{Na}$ Operação Urbana do Izidoro, em implementação em Belo Horizonte, a diversidade social foi neglıgencıada, já que foi proposta uma ocupação voltada para uma população de maior poder aquisitivo, excluindo as famílias de baixa renda.

Operações urbanas, como a do Izidoro, ao desconsiderarem alguns segmentos sociais, contribuem para 0 fomento das desigualdades socioespaciais e dos processos de ocupações. Conclui-se, assim, que a Operação Urbana do Izidoro é ineficaz, posto que não se adequa ao fim social que a justifica, qual seja, a consecução dos interesses e anseios da coletividade, ao se afastar da realidade social e das necessidades reais da população.

Não se olvida a importância do instrumento urbanístico das Operações Urbanas que, além de envolver parcerias para sua concretização, pressupõe, no seu escopo legal, uma ampla participação da população. Entretanto, a ineficiência na implementação dessa legislação se faz presente, ou seja, existe ainda uma distância entre as intenções estabelecidas nos princípios legais e a real efetividade do instrumento.

BELO HORIZONTE. Lei no 813710 de dezembro de 2000. Parcelamento, ocupação e uso do solo de Belo Horizonte. Belo Horizonte, 2000

BELO HORIZONTE. Lei no 995912 de dezembro de 2010. Parcelamento, ocupação e uso do solo de Belo Horizonte. Belo Horizonte, 2010.

BELO HORIZONTE. Prefeitura Municipal. Processo administrativo $n^{\circ}$ 01.16.7621.11.23 da Operação Urbana do Izidoro-Granja Werneck. Belo Horizonte, Secretaria Municipal de Meio Ambiente, 2011. 
BELO HORIZONTE. Prefeitura Municipal.

Estatística e informações históricas sobre Belo Horizonte, 2016. Disponível em:

http://portalpbh.pbh.gov.br/pbh/ecp/busca.do;jsessioni $\mathrm{d}=\mathrm{A} 15 \mathrm{~B} 0 \mathrm{FBFC} 32 \mathrm{C} 147399 \mathrm{CB} 98699 \mathrm{D} 19 \mathrm{~F} 116$. portalpb h1b?busca=informa\%C3\%A7\%C3\%B5es+hist\%C3\%B 3ricas\&evento=Ok. Acesso em: 12 abr. 2016.

BRASIL. Constituição (1988). Constituição da República Federativa do Brasil. 11ª̂.ed. São Paulo: Saraiva, 2011.

BRASIL. Lei no 10.257, de 10 de julho de 2001. Regulamenta os arts. 182 e 183 da Constituição Federal, estabelece diretrizes gerais da política urbana e dá outras providências - Estatuto das Cidades. Brasília, 2001.

CARVALHO FILHO, José dos Santos. Comentários ao Estatuto da Cidade. Lei no 10.257, de 10.07.2001 e Medida Provisória no 2.220, de 04.09.2001. Rio de Janeiro: Editora Lúmen Júris, 2005.

CAVALIERI FILHO, Sérgio. Você conhece sociologia jurídica?. Rio de Janeiro: Forense, 1998. .

\section{DIARIOLIBERDADE. Ocupação do Izidoro.}

Disponível em:

http://www.diarioliberdade.org/brasil/repressom-edireitos-humanos/50901-izidoro-o-maior-conflitoterritorial-urbano-de-minas-gerais.html. Acesso em: 01 de fev. de 2016

IPEA. Problema Habitacional no Brasil: Déficit, Financiamento e Perspectivas. Disponível em: http://www.ipea.gov.br/portal/index.php?option=com_c ontent\&view $=$ article\&id $=3578 \&$ catid $=318$. Acesso em: 12 abr. 2015.

LEFÉBVRE, Henri. The production of space. Oxford, OX, UK; Cambridge, Mass.,USA: Blackwell, 1991.
LOMAR, P. J. V.. Operação Urbana Consorciada (arts. 32 a 34). In: Dallari, Adilson A.; Ferraz, Sergio (Org.). Estatuto da cidade (Comentários à Lei Federal 10.257/2001). São Paulo, Malheiros, 2010.

MARICATO, E. O. 'Minha Casa' é um avanço, mas segregação urbana fica intocada. In: Carta Maior, 27 maio 2009. Disponível em

http://www.cartamaior.com.br. Acesso em: 5 Mar, 2015.

MEIRELLES, H. L.. Direito de Construir. 10.ed. São Paulo: Malheiros Editores Ltda, 2011.

MONTEIRO, L.O.. Espacialidades e especificidades [manuscrito]: as operações urbanas consorciadas como ferramenta de planejamento e de gestão do espaço. Tese (Doutorado) - Universidade Federal de Minas Gerais, Escola de Arquitetura. 2014.

SILVA, J. A.. Direito urbanístico brasileiro. São Paulo: Malheiros, 2014.

SILVA, J. A. da. Aplicabilidade das normas constitucionais. 7 ed. São Paulo: Malheiros Editores Ltda, 2007.

URBEL. Companhia Urbanizadora de Belo Horizonte. Dados sobre Favelas de Belo Horizonte. 2014. Disponível em: http://portalpbh.pbh.gov.br/pbh/ecp/contents.do?event $\mathrm{o}=$ conteudo\&idConteudo $=50532 \& \mathrm{chPlc}=50532 \& \& \mathrm{pldP}$ IC=\&app=salanoticias. Acesso em: 01 de fev. de 2016. 